\title{
Binding Interaction Studies of Selected Receptor Subpopulations after Partial Cross-linking Receptor-Ligand Complexes with a Photoactivated Heterobifunctional Reagent
}

\author{
Guy B. Faguet ${ }^{\star} \neq \S$ and Deborah Beebe $\S$ \\ *Department of Medicine, and $\ddagger$ Department of Cell and Molecular Biology, Medical College of Georgia; \\ and §Medical and Research Services, Veterans Administration Medical Center, Augusta, Georgia 30910
}

\begin{abstract}
Certain hormonal and nonhormonal binding systems such as the leukoagglutinin-lymphocyte model exhibit complex receptor-ligand interactions that result in nonlinear Scatchard plots. Such plots are interpreted as indicating either homogeneous negatively interacting binding sites or heterogeneous sites with different and fixed affinity. We assessed the validity of these interpretations in our system by conjugating the ligand to a photoactivated heterobifunctional agent and cross-linking the conjugate to a subset of receptors before studying the binding interactions of non-cross-linked sites. Conjugation did not qualitatively or quantitatively affect the binding properties of the ligand. Crosslinking was specific, efficient, and stable and had no effect on irrelevant surface receptors. Cross-linking of only 3\% of the total receptors resulted in $\mathbf{5 0 \%}$ decreased ligand binding to high affinity sites consistent with a calculated inactivation of $85 \%$ and $2 \%$ of high and low affinity sites, respectively. Such preferential inactivation of high affinity sites is an unequivocal demonstration of binding site heterogeneity in this system and shows a clear rejection of the homogeneous cooperation model.
\end{abstract}

\section{Introduction}

Evidence suggests that complex receptor-ligand interactions in certain hormonal and nonhormonal systems reflect occupancydependent affinity $(1,2)$. To date, such evidence has relied on demonstrating enhanced dissociation of bound labeled ligand as receptor occupancy is increased by addition of an excess of unlabeled ligand to the dissociation mixture $(1,2)$. While suggestive, this approach fails to prove the existence of negatively interacting binding sites (3-7). Thus, the existence of heterogeneous binding sites with different but fixed affinity for the ligand remains the preferred explanation of such complex binding interactions. Objective resolution of the uncertainty regarding binding models underlying complex binding interactions is hampered by the phenomenological nature of receptor-ligand binding studies and by methodological limitations that preclude selectively studying each class of heterogeneous binding sites. If receptors belonging to one of two distinct classes of binding sites were cross-linked to the ligand, then data from post-cross-linking binding studies would reflect the second non-cross-linked class of receptor. Such an approach might provide an experimental

Address correspondence to Dr. Faguet, VAMC (111N), Augusta, GA 30910.

Received for publication 7 October 1985. basis for distinguishing homogeneous interacting from heterogeneous noninteracting binding sites.

Using the lymphocyte-leukoagglutinin (LPHA), ${ }^{1}$ a receptorligand system that generates binding data compatible with either homogeneous interacting or with heterogeneous binding sites with different and fixed affinities, we have examined the binding interactions of one of the two assumed receptor classes after selectively cross-linking the other receptor class with a photoactivated heterobifunctional reagent. Our observations clearly show that in the LPHA-lymphocyte system, complex binding interactions reflect binding site heterogeneity and are inconsistent with the negatively cooperative model.

\section{Methods}

Cells

IM9, a B-lymphoblastoid cell line, was grown in RPMI 1640 (Gibco, Grand Island, NY) with $10 \%$ fetal calf serum (MA Bioproducts, Walkersville, $\mathrm{MD}$ ) at $37^{\circ} \mathrm{C}$ in a $5 \% \mathrm{CO}_{2}$ incubator (Forma Scientific, Marietta, $\mathrm{OH})$. Before binding assays, cells were harvested by centrifugation at $200 \mathrm{~g}$ for $10 \mathrm{~min}$ and washed three times with medium. Cell viability assessed by Trypan Blue dye exclusion was consistently $>95 \%$.

\section{$P H A$ purification and iodination}

LPHA, a potent mitogenic lectin $(8,9)$, was prepared from a single batch of PHA-P (Difco Laboratories, Inc., Detroit, MI) according to a modification of the column chromatography methods of Weber (8), as previously described (9). LPHA was iodinated (with reductant-free ${ }^{125}$ I or ${ }^{131} \mathrm{I}, 17$ and $20 \mathrm{Ci} / \mathrm{mg}$ sp act, respectively, Amersham Corp., Arlington Heights, IL) by the chloramine-T method of Hunter and Greenwood (10) to a specific activity of $0.1-1 \mu \mathrm{Ci} / \mu \mathrm{g}$. Details of the LPHA purification and iodination procedures, and of its biological activity have been published elsewhere $(9,11,12)$.

\section{Insulin iodination}

Porcine insulin, a gift from Dr. R. Chance (Eli Lilly \& Co., Indianapolis, IN), was iodinated (reductant-free ${ }^{131} \mathrm{I}, 20 \mathrm{Ci} / \mathrm{mg}$ sp act, Amersham Corp.) by the chloramine-T method of Hunter and Greenwood (10) to a specific activity of $100-200 \mu \mathrm{Ci} / \mu \mathrm{g}$.

\section{LPHA conjugation}

Radioiodinated LPHA was conjugated with the heterobifunctional reagent ethyl $\mathrm{N}$-5-azido-2-nitrobenzoylaminoacetimidate-HCl (ANB-AI), a gift from Dr. W. S. Allison (University of California, San Diego, CA), according to published procedure (13). Briefly, after dialysis against 0.15 $\mathrm{M} \mathrm{Na}{ }_{2} \mathrm{CO}_{3}$ buffer, $\mathrm{pH} 9$, overnight at $4^{\circ} \mathrm{C}, 0.5 \mathrm{mg}$ of ${ }^{125}$ I-LPHA was exposed to a 10-fold molar excess of ANB-AI and rotated for $8 \mathrm{~h}$ at room temperature. The reaction mixture was filtered over a G-50 sephadex column (Pharmacia Fine Chemicals, Piscataway, NJ), and equil-

1. Abbreviations used in this paper: ANB-AI, ethyl N-5-azide-2-nitrobenzoylaminoacetimidate-HCl; LPHA, leukoagglutinin. 
ibrated with $0.15 \mathrm{M}$ phosphate buffer, $\mathrm{pH}$ 7.4. The pooled radioactive peak containing the activated radiolabeled lectin ( ${ }^{125} \mathrm{I}-\mathrm{LPHA}-\mathrm{ANB}-\mathrm{AI}$, $0.1-1 \mu \mathrm{Ci} / \mu \mathrm{g} \mathrm{sp}$ act) was in aliquots and stored at $-70^{\circ} \mathrm{C}$. All manipulations of the activated lectin were carried out in the dark.

\section{Receptor-ligand binding studies}

Binding equilibrium. Increasing concentrations $\left(1.5 \times 10^{-9} \mathrm{M}\right.$ to 1.5 $\left.\times 10^{-6} \mathrm{M}\right)$ of ${ }^{131} \mathrm{I}$-LPHA of constant specific activity were incubated with fresh cells ( $10^{6}$ aliquots) or with cell aliquots previously cross-linked with tracer concentrations $\left(2.65 \times 10^{-8} \mathrm{M}\right)$ of ${ }^{125}$ I-LPHA-ANB-AI in $0.5 \mathrm{ml}$ Hanks' buffer containing $0.1 \%$ of bovine serum albumin (BSA; Sigma Chemical Co., St. Louis, MO) in polystyrene tubes precoated overnight with $0.5 \%$ BSA in Hanks' buffer to minimize nonspecific binding. Controls included ${ }^{131}$ I-LPHA binding to fresh cells in the presence of equimolar concentrations of ANB-AI and equilibrium binding of equimolar concentrations of ${ }^{125} \mathrm{I}-\mathrm{LPHA}-\mathrm{ANB}-\mathrm{AI}$ of constant specific activity to fresh cells. After reaching equilibrium $\left(60 \mathrm{~min}\right.$ incubation at $\left.22^{\circ} \mathrm{C}\right)$ the bound and unbound tracer from each incubation were separated by centrifugation over a 4:1 mixture of dibutyl phthalate and bis-2-ethylhexyl phthalate (Eastman Kodak Co., Rochester, NY) at 10,000 $g$ (Microfuge 12; Beckman Instruments, Inc., Fullerton, CA) for 2 min in conical microcentrifuge tubes (Sarstedt, Inc., Princeton, NJ). The centrifuge tube tips containing the cell pellet were cut off and cell-bound radioactivity of the pellet was determined in a gamma counter (Gamma 4000; Beckman Instruments, Inc.). Aliquots of cells cross-linked with ${ }^{125}$ I-LPHAANB-AI but not exposed to ${ }^{131}$ I-LPHA were counted to determine the amount and efficiency of cross-linking. In some experiments binding of ${ }^{125} \mathrm{I}$-insulin to IM-9 cells under steady state was determined as described for LPHA except that cells were incubated with ${ }^{125}$ I-insulin $\left(1.7 \times 10^{-11}\right.$ $M)$ in the presence of increasing concentrations of native insulin.

Dissociation studies. Cells $\left(10^{6}\right.$ aliquots) were exposed to tracer amounts $\left(2.65 \times 10^{-8} \mathrm{M}\right)$ of ${ }^{125}$ I-LPHA or ${ }^{125} \mathrm{I}$-LPHA-ANB-AI in 0.1 $\mathrm{ml}$ of Hanks' buffer containing $0.1 \%$ BSA (Hanks'-BSA). After reaching equilibrium, cells were irradiated and unbound tracer ligand was removed by washing the cells twice with Hanks'-BSA buffer at $4^{\circ} \mathrm{C}$ and replacing the supernatant with 50 volumes of Hanks'-BSA buffer alone or in buffer containing native LPHA in concentrations equal to the ${ }^{125}$ I-LPHA present in the original sample. Volume dilution prevents reassociation of ligand released during the dissociation reaction $(1,2)$. Addition of native LPHA increases the overall occupancy by the ligand and thus enhances tracer dissociation, as described for this (2) and other systems (14). At various times, duplicate cell aliquots were processed as described above to ascertain receptor ligand complex dissociation.

\section{Receptor-LPHA cross-linking}

Cross-linking was induced as follows: After equilibration with tracer concentrations of ${ }^{125} \mathrm{I}$-LPHA-ANB-AI, cells were placed in a BSA-precoated quartz glass tube and irradiated for $5 \mathrm{~min}$. Irradiations were carried out in a Rayonet photochemical reactor (RMR-500; Southern New England Ultraviolet Co., Hamden, CT). The apparatus contains four fluorescent tubes with an output of 975 milliwatts each at $300 \mathrm{~nm}$ arranged around a cylinder. This long wavelength light increases the reactivity of the photo-generated arylnitrene and reduces undesirable photolysis on other amino acid residues of the conjugated protein (15). The samples in glass tubes rotate at $5 \mathrm{rpm}$ in a carousel (Merry-go-round, RMR-400; Southern New England Ultraviolet Co., Hamden, CT), insuring uniform irradiation of all samples.

\section{Data analysis}

Specific LPHA and insulin binding was calculated from total binding by subtracting nonspecific binding, as determined by binding of radioligand in the presence of 1,000 -fold excess of native ligand. Data from dual radiolabel experiments were corrected for spilldown of ${ }^{131}$ I counts into the ${ }^{125} \mathrm{I}$ window. Data are presented as averages of replicate experiments as indicated in the figure legends. In all experiments, each data point is assessed in duplicate. Standard deviations (not shown) were gen- erally $<5 \%$ of the mean. Equilibrium binding data were analyzed by curve-fitting using the least-square "ligand" program (16) adapted to Apple Soft Basic for the Apple II+ microcomputer (Apple Computer, Inc., Cupertino, CA). Fitted parameters are displayed in Scatchard coordinates (17).

\section{Results}

Properties of the ${ }^{125}$ I-LPHA-ANB-AI conjugate. Fig. 1 shows the radioactivity, protein, and ANB-AI profiles of the fractionation eluate of the modified ${ }^{125}$ I-LPHA. As shown, nearly all the modified ${ }^{125}$ I-LPHA eluted between fractions 11 and 16 with clearcut separation between the conjugated and the unconjugated fractions of ANB-AI. The figure inset shows the absorption spectra of the modified and unmodified LPHA. Based on the extinction coefficient of ANB-AI $\left(\epsilon=9 \times 10^{3} \mathrm{M}^{-1}\right.$ at $\left.318 \mathrm{~nm}\right)$, the molecular weight of LPHA $(128,000)$, and the contribution of ANB-AI to the modified LPHA absorbance at $318 \mathrm{nM}$, the molar ratio of reagent to lectin can be estimated. Reaction conditions were chosen to generate conjugates with an ANB-AI to LPHA molar ratio of 1 . Because one cross-link is sufficient, such a ratio reduces undesirable cross-linking to nonreceptor surface moieties often associated with excesses of heterobifunctional reagent.

Effect of ANB-AI on LPHA binding. Whether or not ANBAI affects the magnitude or affinity of LPHA binding to lymphocyte receptors was ascertained in the following experiments. Cells were equilibrated either with $1.5 \times 10^{-9} \mathrm{M}$ to $1.5 \times 10^{-6}$ $\mathrm{M}$ of ${ }^{131} \mathrm{I}$-LPHA in the presence and absence of equimolar concentrations of ANB-AI or with $1.5 \times 10^{-9} \mathrm{M}$ to $1.5 \times 10^{-6} \mathrm{M}$ ${ }^{125}$ I-LPHA-ANB-AI conjugate as described under Methods. As shown in Fig. $2 A$, binding of LPHA to its lymphocyte receptors was substantially the same at all ligand concentrations in each set of experiments. Replots in Scatchard coordinates (Fig. 2 B) show that binding data from each set of experiments generates a virtually identical curvilinear Scatchard plot. Thus, under these experimental conditions, ANB-AI does not affect the magnitude or complexity of LPHA binding either as unconjugated reagent in the reaction mixture or when conjugated to the binding ligand.

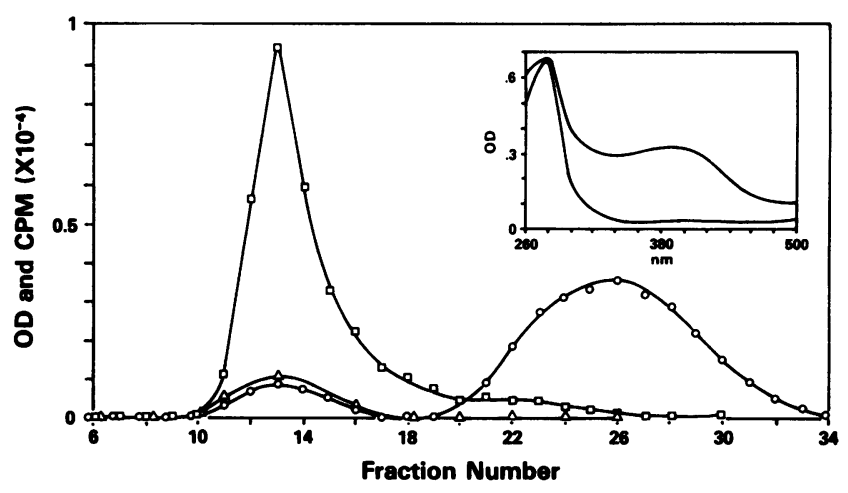

Figure 1. Chromatography of ${ }^{125}$ I-LPHA conjugated with ANB-AI on sephadex G-50. Each tube contained $0.5 \mathrm{ml}$ of effluent. Fractions were assayed for the presence of radioiodine ( $\square$ ) in a gamma counter; protein $(\Delta)$ at $700 \mathrm{~nm}$ absorbance; and for presence of ANB-AI (O), at 405 $\mathrm{nm}$. The inset shows the absorption spectra of conjugated (upper line) and unconjugated (lower line) LPHA. 

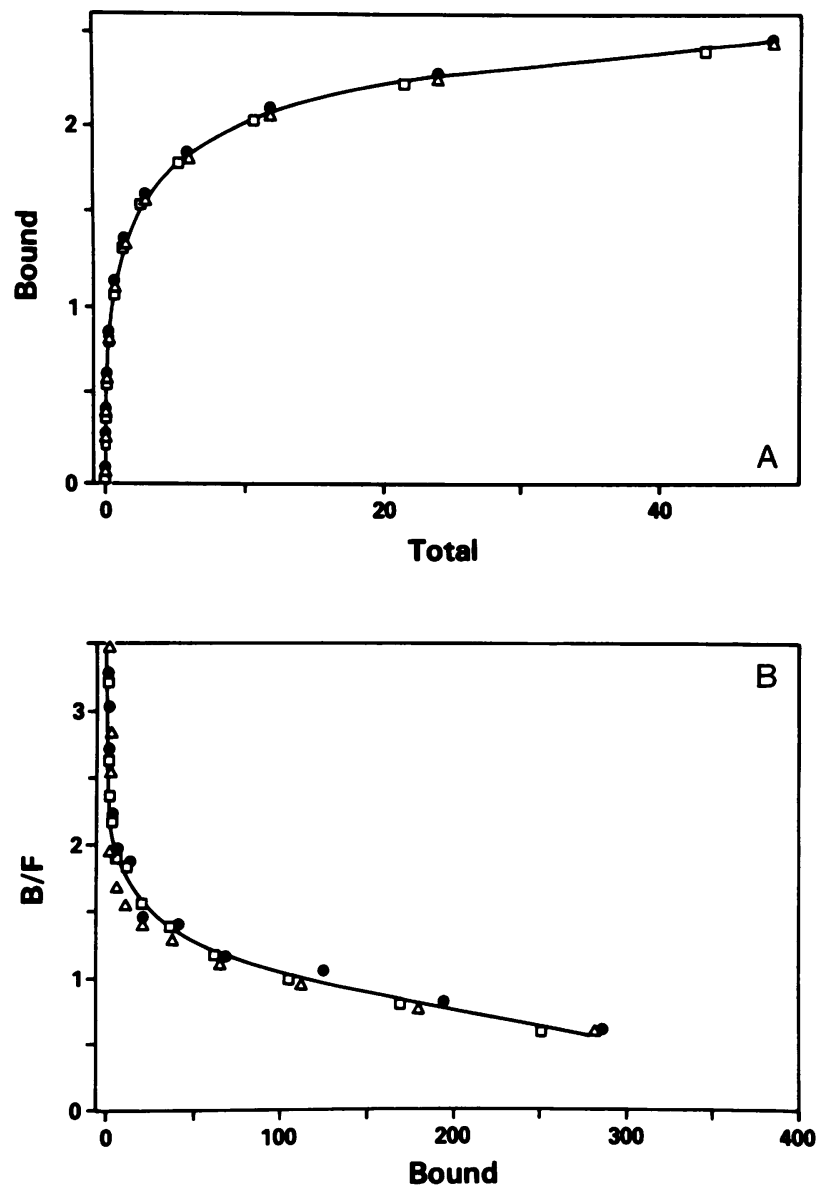

Figure 2. (A) Binding of ${ }^{131}$ I-LPHA and ${ }^{125}$ I-LPHA-ANB-AI to IM9 cells. Cells were equilibrated with increasing concentrations of ${ }^{131} \mathrm{I}$ LPHA in the presence $(\Delta)$ and absence ( $\square$ ) of ANB-AI and with increasing concentrations of ${ }^{125}$ I-LPHA-ANB-AI (๑). Cell-bound radioactivity was measured in duplicate aliquots of $10^{6}$ cells as described in the text. Receptor-bound ligand is expressed as bound (log of $\mathrm{ng}^{125} \mathrm{I}-$ LPHA $/ 10^{6}$ cells) and is plotted as a function of the total ligand added $\left(\mu \mathrm{g} / 10^{6}\right.$ cells). (B) Replots the binding data in Scatchard coordinates. Bound over free radioiodinated ligand is expressed as a function of bound ( $\mathrm{ng} \times 10^{6}$ cells).

Assessment of cross-linking. To assess cross-linking efficiency, two sets of $8 \times 10^{6}$ cells were incubated with tracer amounts $\left(2.65 \times 10^{-8} \mathrm{M}\right)$ of ${ }^{125} \mathrm{I}$-LPHA or ${ }^{125} \mathrm{I}$-LPHA-ANB-AI, respectively. After reaching equilibrium, both sets were simultaneously irradiated as described above, washed twice in Hanks'-BSA buffer, and diluted with a 50-fold excess of Hanks'-BSA buffer alone, or in buffer containing native LPHA at concentrations $\left(2.65 \times 10^{-8} \mathrm{M}\right)$ sufficient to maintain equilibrium initially induced by the tracer (2). Duplicate aliquots of $10^{6}$ cells were removed from each set at $0,5,30$, and $60 \mathrm{~min}$ and processed as described above to ascertain cell-bound radioactivity. Under these experimental conditions, dissociation of receptor-ligand complexes proceeds spontaneously (basal dissociation) or is accelerated by the presence of excess of native ligand in the reaction mixture (ligand-enhanced dissociation) as demonstrated for this (2) and other systems $(1,14)$. As shown in Fig. $3 A$, spontaneous and LPHA-enhanced tracer dissociation were 37 and $68 \%$, respectively, at $60 \mathrm{~min}$. These values are comparable to dissociation experiments performed on nonirradiated lymphocytes (2). In
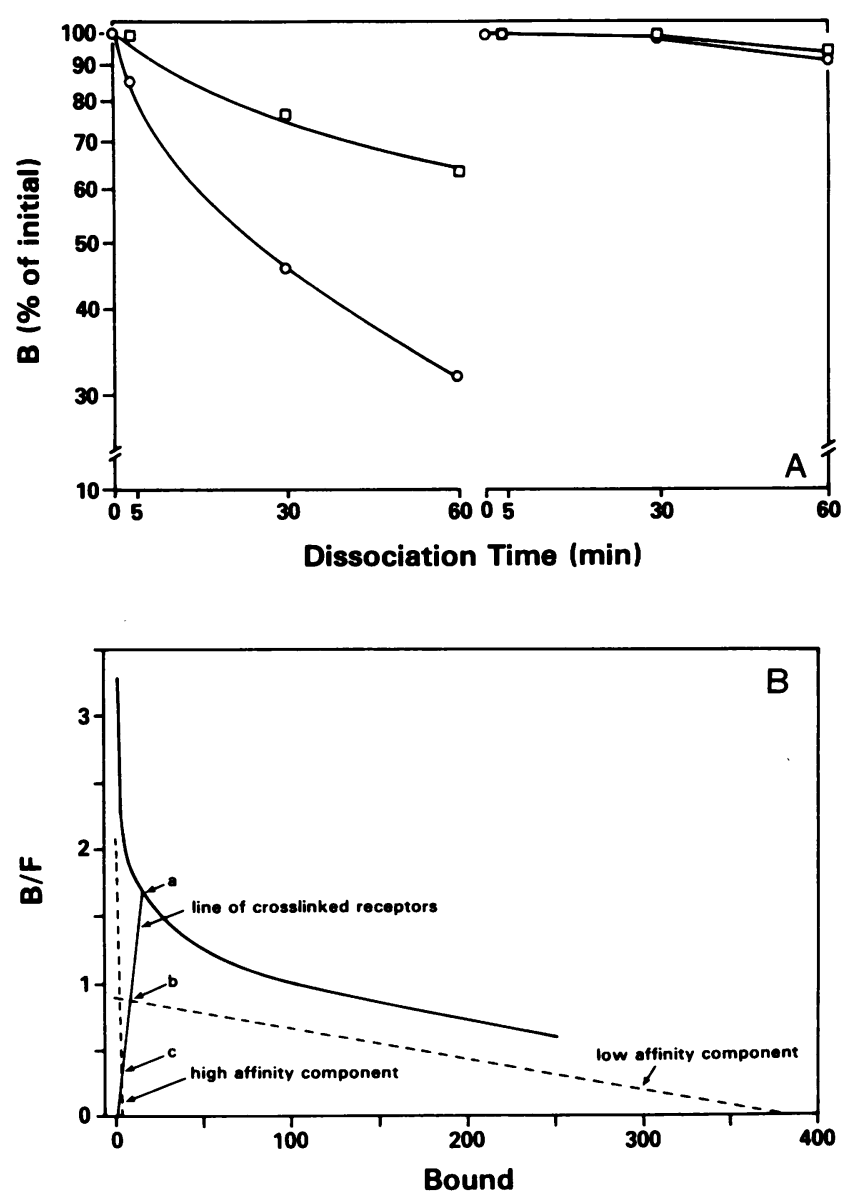

Figure 3. (A) Dissociation of receptor-LPHA complexes. After equilibrating with tracer amounts $\left(2.65 \times 10^{-8} \mathrm{M} / 10^{6}\right.$ cells $)$ of ${ }^{125} \mathrm{I}$-LPHA (left) or ${ }^{125}$ I-LPHA-ANB-AI (right), cells were irradiated and washed twice with buffer. Supernatants were replaced by a 50 -fold excess of fresh medium containing (o, set 1 ) or not containing ( $\square$, set 2$) 2.65$ $\times 10^{-8} \mathrm{M}$ of native LPHA per $10^{6}$ cells. At the intervals shown, duplicate aliquots from each set were processed as described in the text to ascertain the cell-bound radioconjugated ligand. Data are expressed as percentages of time zero value and plotted as a function of dissociation time. $(B)$ Scatchard plots of ${ }^{131} \mathrm{I}$-LPHA equilibrium binding to IM9 cells before cross-linking showing the high and low affinity components of the curve. The fraction of total cross-linked receptors ( $a$ $=13 \mathrm{ng} / 10^{6}$ cells) linearly extrapolates to the high and low affinity components intersecting at $b=3 \mathrm{ng} / 10^{6}$ cells and $c=9 \mathrm{ng} / 10^{6}$ cells, respectively. Ratio of bound over free ${ }^{131}$ I-LPHA $(\times 100)$ is plotted as a function of bound ${ }^{131}$ I-LPHA (ng $\times 10^{6}$ cells).

contrast, irradiation of cells equilibrated with ${ }^{125}$ I-LPHA-ANBAI precluded both spontaneous and LPHA-enhanced dissociation of receptor-bound ${ }^{125}$ I-LPHA-ANB-AI. As shown, 95 and $92 \%$ of receptor- ${ }^{125}$ I-LPHA-ANB-AI complexes remained crosslinked under basal and LPHA-enhanced conditions, respectively, after 60 min dissociation.

Binding interactions after cross-linking one of two (assumed) classes of receptors. In this system, LPHA-receptor binding interactions data generate a curvilinear Scatchard plot (Fig. 3 B) compatible with more than one class of sites with different and fixed affinity, or with one class of interacting binding sites. Assuming heterogeneous sites, the Scatchard plot was mathematically resolved by weighted nonlinear least-squares curve fitting 
to estimate the equilibrium binding constants ( $K$ and $R$ values) of each binding class. A two-site model was identified as "best fit" consisting of a small component $\left(R_{1}=3.6 \mathrm{ng} / 10^{6}\right.$ cells) of high affinity sites $\left(K_{1}=2 \times 10^{9} \mathrm{M}^{-1}\right)$; and a large component $\left(R_{2}=388 \mathrm{ng} / 10^{6}\right.$ cells $)$ of low affinity receptors $\left(K_{2}=5 \times 10^{6}\right.$ $\mathbf{M}^{-1}$ ). Using dual labeled ligand, we conducted equilibrium binding studies using ${ }^{131}$ I-LPHA on the assumed class of low affinity sites after cross-linking the assumed class of high affinity receptors (with ${ }^{125}$ I-LPHA-ANB-AI) as described under Methods. Cell aliquots equilibrated with ${ }^{131}$ I-LPHA in the presence or absence of ANB-AI followed by irradiation and cells equilibrated with ${ }^{131}$ I-LPHA-ANB-AI without irradiation served as controls. The fraction of cross-linked receptors $\left(13 \mathrm{ng} / 10^{6}\right.$ cells or $\sim 3 \%$ of the total) exceeded (by >3:1) the estimated capacity of high affinity sites, thus insuring that equilibrium binding data generated under these conditions reflect mostly low affinity site interactions minimally contributed to by the class of high affinity sites. This prediction was graphically confirmed from the intersection of the line of cross-linked receptors (Fig. $3 \mathrm{~B}$ ) with the low and high affinity components of the Scatchard plot, which shows that 2 and $85 \%$ of the assumed low and high affinity receptors, respectively, were inactivated. The latter estimate is further supported by curve fitting of the Scatchard plot following cross-linking which revealed a $15 \%$ remnant active high affinity class $\left(0.56 \mathrm{ng} / 10^{6}\right.$ cells). ${ }^{131} \mathrm{I}$-LPHA binding to cross-linked cells (Fig. 4, solid squares) generated a curvilinear Scatchard plot qualitatively comparable to those derived from ${ }^{131}$ I-LPHA binding to non-cross-linked cells (Fig. $2 \mathrm{~B}$, open squares, open triangles, and solid circles) but with a $50 \%$ decrease in binding to high affinity sites.

Insulin binding to ${ }^{125}$ I-LPHA-ANB-AI cross-linked cells. To ascertain the specificity of receptor-ligand cross-linking and to assess the potential effect of cross-linking on the cell membrane and on unrelated membrane components, we performed the following experiments: cell aliquots were equilibrated with ${ }^{125} \mathrm{I}$ LPHA-ANB-AI and in the presence of an excess of native LPHA. Excesses of native LPHA blocked binding of the conjugated ligand to specific receptors resulting in a binding component comparable to the unsaturable nonspecific binding obtained from blanks (not shown). In addition, equilibrium ${ }^{131} \mathrm{I}$-insulin binding experiments were conducted on IM9 cells cross-linked with ${ }^{125} \mathrm{I}$ LPHA-ANB-AI. Insulin was chosen as a second ligand because the density ratio of LPHA to insulin receptors on IM9 cells is $\sim$ 100:1 (G. B. Faguet, unpublished observations). Thus, binding interactions of low density receptors would be appreciably altered by cross-linking even a small fraction of the high density receptors should the cross-linking be either partly nonspecific or should it induce allosteric effects. Fig. 5 shows the Scatchard display of insulin binding to fresh IM9 cells and to IM9 cells pre-crosslinked with LPHA. The fraction of cross-linked LPHA was calculated at $17 \mathrm{ng} / 10^{6}$ cells or $\sim 80,000$ receptors per cell. Likewise, it is calculated that $109-3,135$ insulin receptors per cell were bound with insulin. Thus, the ratio of LPHA cross-linked to insulin-bound receptors over the insulin concentration range assayed was 736:1 to 26:1. Insulin binding to LPHA cross-linked and non-cross-linked IM9 cells was virtually identical, which strongly suggests that LPHA-receptor cross-linking had no effect on the binding interactions of non-LPHA receptors. This suggests that LPHA cross-linking was receptor-specific, exerted no measurable allosteric effects, and did not affect the complex interactions of irrelevant receptors.
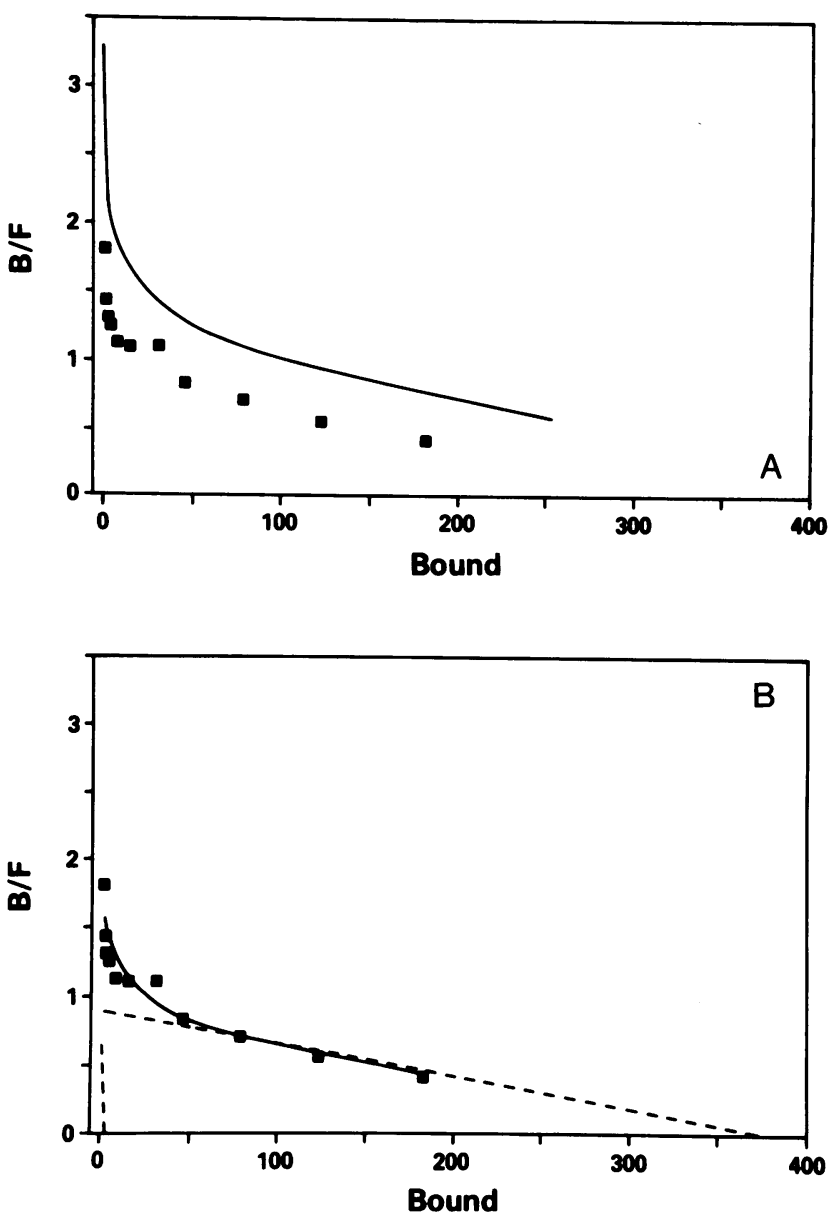

Figure 4. Scatchard plot of ${ }^{131}$ I-LPHA equilibrium binding to IM9 cells after $3 \%$ receptor inactivation ( $\square$ ) compared with expected curves for remaining sites assumed homogeneous and negatively interacting $(A)$, or postulated heterogeneous with high and low components $(B)$.

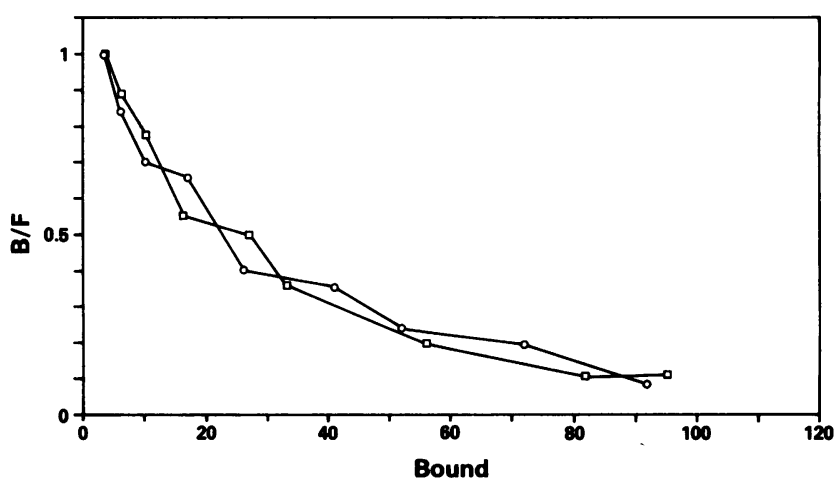

Figure 5. Scatchard plots of insulin binding to fresh and LPHA-crosslinked IM9 cells. ${ }^{125} \mathrm{I}$-insulin $\left(1.7 \times 10^{-11} \mathrm{M}\right)$ was incubated for 90 $\min$ at $15^{\circ} \mathrm{C}$ with two sets of $2 \times 10^{6} \mathrm{cells} / \mathrm{ml}$ in the presence and absence of various concentrations of native insulin. One set consisted of fresh cells ( $\square$ ), the other of cells that had been preincubated with ${ }^{131} \mathrm{I}$ LPHA and irradiated (O) as described in the text to cross-link a fraction of LPHA receptors. Specific ${ }^{125} \mathrm{I}$-insulin binding was determined and the bound over free ratio of labeled hormone is plotted as a function of the total concentration of bound hormone. 


\section{Discussion}

This report shows that a select fraction of LPHA receptors can be cross-linked to LPHA by the heterobifunctional agent ANB$\mathrm{AI}$ and that selective binding interaction studies can be conducted on the non-cross-linked receptor population. One attractive feature of the heterobifunctional agent ANB-AI is that it can be activated with $300 \mathrm{~nm}$ ultraviolet light (13) reducing to a minimum radiation damage to the target $(13,18)$. This is of particular importance when intact cells are involved. Crucial to the interpretation of our results, and the validity of our conclusions, is the assessment of the specificity and efficiency of cross-linking; the distinction between cross-linked and non-cross-linked receptors; and the evaluation of the possible contribution of biological cross-linking during photolysis $(19,20)$. The specificity of binding and cross-linking LPHA-ANB-AI to lymphocyte LPHA receptors is shown by complete inhibition of LPHA-ANBAI binding by native LPHA and the fact that LPHA receptor cross-linking had no effect on the binding interactions of irrelevant insulin receptors. A significant degree of random chemical or biological cross-linking would be expected to qualitatively or quantitatively affect binding of irrelevant receptors particularly at such a high density of the target receptor $\left(3.4 \times 10^{6} /\right.$ cell $)$ and with a 100:1 target/irrelevant receptors ratio. Irradiation was determined to induce efficient cross-linking as $\sim 100 \%$ of LPHAANB-AI bound to receptors at the time of irradiation was crosslinked by photolysis. By virtue of the 1:1 LPHA/ANB-AI molar ratio of the activated lectin, this cross-linking efficiency suggests that the ANB-AI attaches LPHA very near its binding site. Stability of cross-linked complexes is demonstrated by the minimal spontaneous dissociation $(\sim 5 \%)$ of receptor-bound and irradiated LPHA-ANB-AI over a 60 -min period (compared with $37 \%$ for LPHA), and the fact that dissociation of cross-linked complexes was not enhanced by excess of native ligand. Assessment of the potential effect of cross-linking binding a fraction of receptors on the post-cross-linking binding data must be examined in the context of the opposing hypothetical binding models: homogeneous interacting binding sites with occupancy-dependent affinity vs. heterogeneous classes of sites with different and fixed affinity. Cross-linking of a fraction of binding sites would have no appreciable effect on binding interactions of the remaining non-cross-linked receptors if all receptors belong to a single class of interacting binding sites. Indeed, non-cross-linked receptors would retain variable affinity dependent on occupancy. According to this model, data from equilibrium binding studies conducted on non-cross-linked receptors would generate identical curvilinear Scatchard plots regardless of whether a fraction of receptors is cross-linked. In contrast, in a system with two classes of noninteracting binding sites with different and fixed affinity binding, studies performed after preferential inactivation of a class of sites will reflect interactions of the non-cross-linked class. According to this model, the magnitude and class specificity of the inactivation will dictate the extent to which the pre- and post-inactivation Scatchard plots differ. In our system we found that inactivation of only $3 \%$ of the total receptors by cross-linking, resulted in a 50\% decrease in subsequent tracer ligand binding to high affinity sites. This preferential inactivation of high affinity sites represents an unequivocal demonstration of binding site heterogeneity in this system and a clear rejection of the homogeneous negatively cooperative binding model. Indeed, graphical analysis of the Scatchard plot indicates that cross-linking inactivation of $3 \%$ of the total receptors eliminates $85 \%$ of the low capacity-high affinity receptors but only $2 \%$ of the high capacitylow affinity sites (Fig. $3 \mathrm{~B}$ ), which is consistent with a two-class heterogeneous binding site interpretation (Fig. 4). It could be argued that the receptor-LPHA-ANB-AI complex dissociates but that the conjugate remains cross-linked by the ANB-AI at a site other than the LPHA receptor. Should this be the case, crosslinking would have no effect on binding interactions because, in effect, all receptors would remain available to the unconjugated tracer ligand. However, two conditions must be met for this to occur: $(a)$ cross-linking would have to be random rather than receptor-specific, and $(b)$ the association constant of the unconjugated ligand should be greater than the dissociation rate of the conjugated ligand (concerted substitution hypothesis). However, such alternative explanation of our data is inconsistent with our findings that cross-linking is receptor-specific and that conjugation did not measurably affect the dissociation constant for the ligand. We did not examine and therefore cannot extrapolate our conclusions to other systems with complex binding interactions. However, given the striking similarities in equilibrium and kinetic binding data derived from LPHA and certain other ligands $(2,4,9,14)$, it is unlikely that our observations represent a phenomenon restricted to LPHA receptors.

\section{Acknowledgments}

The authors thank the reviewer for helpful comments and $M$. A. Jones and P. A. Thompson for typing the manuscript.

This work was supported in part by the Veterans Administration.

\section{References}

1. DeMeyts, P., J. Roth, D. M. Neville, J. Garvin III, and M. A. Lesniak. 1973. Insulin interactions with its receptors: experimental evidence for negative cooperativity. Biochem. Biophys. Res. Commun. 55: 154-161.

2. Faguet, G. B. 1979. Leukoagglutinin binding to human lymphocytes: experimental support for negative cooperativity. Am. J. Physiol. 237(3):E207-E213.

3. Cuatrecasas, P., and M. A. Hollenberg. 1975. Binding of insulin and other hormones to non-receptor materials: saturability specificity and apparent negative cooperativity. Biochem. Biophys. Res. Commun. 62:31-41.

4. Pollet, R. M., M. L. Standaert, and B. A. Haase. 1977. Insulin binding to human lymphocyte receptor. Evaluation of the negative cooperativity model. J. Biol. Chem. 252:5828-5834.

5. Verries, B., G. Fayet, and S. Lissitzky. 1974. Thyrotropin-binding properties of isolated thyroid cells and their purified plasma membranes. Relation of thyrotropin-specific binding to adenylate-cyclase activation. Eur. J. Biochem. 42:355-365.

6. Limbird, L. E., P. DeMeyts, and R. J. Lefkowitz. 1975. Betaadrenergic receptors: evidence for negative cooperativity. Biochem. Biophys. Res. Commun. 64:1160-1168.

7. Sandvig, K., Olsnes, and A. Pihl. 1978. Interactions between abrus lectins and sephadex particles possessing immobilized desialylated fetuin. Eur. J. Biochem. 88:307-313.

8. Weber, T. H. 1969. Isolation and characterization of a lymphocyte stimulating leukoagglutinin from red kidney beans. J. Clin. Lab. Invest. 14(Suppl. III): 1-80.

9. Faguet, G. B. 1977. Mechanisms of lymphocyte activation. Binding kinetics of phytohemagglutinin to human lymphocytes. J. Biol. Chem. 252:2095-2100. 
10. Hunter, W. M., and F. C. Greenwood. 1962. Preparation of iodine- ${ }^{131}$ labeled human growth hormone of high specific activity. Nature (Lond.). 194:495-496.

11. Faguet, G. B. 1979. Mechanisms of lymphocyte activation. The role of suppressor cells in the proliferative responses of chronic lymphatic leukemia lymphocytes. J. Clin. Invest. 63:67-74.

12. Faguet, G. B. 1976. Mechanisms of lymphocyte activation. II. Negative cooperativity in the binding of phytohemagglutinin (PHA) to its lymphocyte receptors. In Leukocyte Membrane Determination Regulating Immune Reactivity. V. P. Eijsvoogle, D. Ross, and W. P. Zeiglemaker, editors. Academic Press, Inc., New York. 65-72.

13. Lewis, R. V., M. F. Roberts, E. A. Dennis, and W. S. Allison. 1977. Photoactivated heterobifunctional cross-linking reagents which demonstrate the aggregation state of phospholipase $A_{2}$ biochemistry. 16 : 5650-5654.

14. DeMeyts, P. 1976. Cooperative properties of hormone receptors in cell membranes. J. Supramol. Struc. 4:241-258.

15. Vladimirov, Y. A., D. J. Roshchupkin, and E. E. Fesenko. 1970.
Photochemical reactions in amino acid residues and inactivation of enzymes during $\mu \mathrm{v}$ irradiation: a review. Photochem. Photobiol. 11:227246.

16. Munson, P. J., and D. Rodbard. 1980. A versatile computerized approach for characterization of ligand-binding systems. Anal. Biochem. 107:220-239.

17. Scatchard, G. 1949. The attraction of proteins for small molecules of ions. NY Acad. Sci. 51:660-672.

18. Fleet, G. W., J. R. Knowles, and R. R. Porter. 1972. The antibody binding site. Labelling of a specific antibody against the photo-precursor of an aryl nitrene. Biochem. J. 128:499-508.

19. Scandella, C. J., P. Devaux, and H. M. McConnell. 1972. Rapid lateral diffusion of phospholipids in rabbit sarcoplasmic reticulum. Proc. Natl. Acad. Sci. USA. 69:2056-2060.

20. Schlessinger, J., D. E. Koppel, D. Axelrod, K. Jacobson, W. W. Webb, and E. L. Elson. 1976. Lateral transport of cell membranes: mobility of concanavalin-A receptors on myeloblasts. Proc. Natl. Acad. Sci. USA. 73:2409-2413. 